\title{
Perspectives and strategies for effective nutrition education
}

\section{By D. J. ODdy, School of Business and Social Studies, Ealing Technical College, Ealing, London $W_{5}{ }_{5} R F$}

A prerequisite for a discussion of effective nutrition education is the establishment of the premise that nutrition is a specific and separate branch of the life sciences. The nutritionist must be similarly identifiable as having a distinct role and professional function. Recent discussions of the state of nutrition have been equivocal on this point: the Neuberger report (ARC/MRC Committee, 1974), for example, unfortunately stresses both the interdisciplinary nature of the subject and its functional relationship with medicine. A major problem, therefore, which nutritionists have as yet failed to solve in Britain is the need to establish this professional role and, in turn, to create an institutional framework within which some assessment of their relationship with associated disciplines may be made and the impact of nutritional education may be evaluated.

One of the most remarkable aspects of the development of the science of nutrition earlier in this century was the receptivity of public opinion in Britain to its findings. The Ministry of Health first established an Advisory Committee on Nutrition as early as I93I. However, public attention focussed on nutritional problems in February 1933, when it was reported that rehousing families in Stockton-on-Tees was reducing dietary intake (M'Gonigle, 1933) and there appeared at the same time an emotive correspondence on the subject of 'Hungry England' (Week-End Review, 1933). In the following 5 years, numerous journals carried articles the essence of which was that the new science of nutrition had become a tool in the formulation of social policy. Pressure groups such as the Children's Minimum Council and the Campaign Against Malnutrition were formed to highlight particular nutritional problems of the period and, in 1935, the Ministry of Health established a new Advisory Committee on Nutrition 'to inquire into the facts, quantitative and qualitative, in relation to the diet of the people, and to report as to any changes therein which appear desirable in the light of modern advances in the knowledge of nutrition'. In its first report (Ministry of Health, 1937) the Committee recognized the need to apply 'the lessons of recent nutritional science to the feeding of the nation', perhaps one of the first nutritional education programmes. While much effort went into the collection of data, little of it had been analysed or could be acted upon before 1939; indeed, some of the schemes introduced, such as the provision of cheap school mill, were only partially implemented and reflected economic demands for the stabilization of milk prices by the producers rather than nutritional requirements (Carr-Saunders, 1937). Furthermore, in reading the debate nearly 40 years later, it is impossible to avoid feeling that public opinion seeking improved nutritional status found readier 
acquiescence in government departments because of the nearness of war (Marrack, 1937). Nevertheless, the fact remains that in the r 930 s attempts were made to formulate a national food policy and that this was successfully applied in the period 1939-53. This wartime food policy was based on the physical control and distribution of food supplies which amounted to the removal, to a very large extent, of consumer choice. It was therefore, by its nature, only a short-term policy, since the return to consumer choice within the post-war period was, in essence, a return to inequality.

Perhaps nutritionists had been too successful in their initial impact and effect on social policy, for there was no major role allocated to them in the reorganization of medical and social services in the late 1940s. The politics of the establishment of the National Health Service concentrated on the medical profession's demand to retain contact between general practitioner and patient rather than a logical attempt to plan and develop an integrated social and health service. One might express some surprise at this apparent omission of the nutritionist from the new post-war social services because there was, in the late 1940 , no obvious prosperity ahead and the welfare state seemed likely to come into operation as part of the new economic and social apparatus for raising society out of the type of depression that had existed in the r930s.

By the time the National Health Service had come into being, therefore, nutritional knowledge or advice could only be obtained by the public either through treatment by a general practitioner as a patient or, alternatively, through commercial advertising and the agency of the food and drug industries. Let us consider the implication of disseminating nutritional knowledge in this way. Once the medical relationship has been established (and estimates have put one nutritional problem alone, obesity, as high as $\mathrm{I} \cdot 5 \%$ of all medical consultations (Office of Health Economics, 1969)), expectations are generated among patients of curative treatment. In turn this has become the deficiency of the general practitioner's response: that prescription (even of a placebo) will satisfy the patient. The limitations on time and facilities make long-term supervision of nutritional problems very difficult and reinforce the pressures which make him resort to chemotherapy; this only emphasizes the curative rather than the preventive function of the health service. Thus the health service provides the authority-structure through which information and advice is channelled, and the nutritionist is almost completely excluded except in extreme clinical cases.

The other major outlet for the dissemination of nutritional information is through the food industry. Here again, the nutritionist has very limited influence because there has been, at least in the past, an inherent contradiction between the interests of food technologist and nutritionist. The food technologist is concerned with quality, preservation and processing, leading ultimately, perhaps, to new foods and increased consumer demand rather than nutritive value. Tape \& Sabry (1969) have gone as far as to suggest that: "The food industry appears to consider nutritionists 'persona non grata' and seldom includes them in research and development teams, except perhaps in companies marketing pet foods'. It is therefore not surprising that matters which in recent years were de facto changes 
in social policy, such as the withdrawal of free school milk, on which nutritionists should undoubtedly have been consulted, were not the subject of any careful discussion or the result of survey findings, but were simple decisions by the Treasury.

Given, therefore, that there is institutional resistance to nutrition education, the nutritionist is also faced with the separate problems of assessing the low level of nutritional knowledge in the community, and of understanding the psychology of likes and dislikes and habit formation. In addition a particular problem which the nutritionist faces is that of the preconception, inherent among educated peoples in the developed world, that man is a rational being and that his dietary habits are formed accordingly. It has been clearly summarized by Pyke ( 1967 ): 'The dogma of the West, which it is heresy to challenge, is that our dietary habits are based on reason: it is only remote foreign tribes which believe in taboos'. My impression is that the meetings of our own Society reinforce this view: it is 20 years since we last discussed nutrition education; in the last to years we have probably put more emphasis on discussing the food habits of minority groups than on discussing those of the British population as a whole. We have devoted little time, if any, to discussing patterns of early emotional behaviour and their effect on the formation of food habits. Yet the nutritionist, if he seeks to alter food habits, will recognize that the ability to diagnose emotional stresses and psycho-social pressures on an individual which have nutritional implications would be an important asset. Even more so, it would depend for success upon the availability of nutritional advice to a vulnerable person which, if accepted, might modify behaviour for some considerable time.

An obvious example occurs when a woman is given her newly-born infant, particularly her first-born. What advice is available to her? Almost certainly not that of an experienced nutritionist if the baby has been born in the average National Health Service hospital. The immediate pressures are threefold: first, the nursing staff, second, other mothers in the same ward, and third, the commercial products which the hospital has in stock. There is enormous variation in the attitudes to breast-feeding and in the amount of encouragement offered. The vulnerability of the mother at this stage has been heavily exploited by the food industry which produces not only the 'baby' milks and foods but also a huge amount of advertising disguised as educational material. No young woman is likely to escape their impact in school or through magazines or infant welfare clinics. The success of this, or any other advertising in any medium, is that it excites interest and at the same time relieves individuals of the anxiety of making choices about which they feel in some way inadequate. In a hospital, few, if any, of the nursing staff will have sufficient scientific knowledge to discriminate confidently between valid information, 'old wives' tales', and advertisements. The woman in the next bed may tell the new mother that breast-feeding is dirty (Newson \& Newson, 1963) or that her husband won't want her to spoil her figure, and most nurses will willingly bring a bottle of a commercial milk preparation in which event the baby's first meal is of a 'convenience' food. Thus it is during the first week of a baby's life and in the weeks immediately after her discharge from hospital that the mother is 
most receptive to advice on feeding patterns and habits for her child. She may see a health visitor or general practitioner, but one person she will not see is the nutritionist. Weaning brings new stress. Once again most of the advice to the mother, often cleverly disguised, is from the food industry. Feeding in the early years of life can add a creative dimension to the mother-child relationship, but this is not likely to be obtained by opening tins of sterile, beige sludge. The effect of this, all too often, is that by the time the child is 2 or 3 years old he may already refuse to eat certain foods, perhaps eggs or milk or vegetables (although a child refusing sweets, crisps, chocolate or soft drinks would be a rare phenomenon).

Thus the nutritionist is generally not consulted (indeed, has no means of access) at a period of very high motivation in a mother's life. The teenager or young adult with a weight problem that affects acceptability by the peer group may also be highly motivated, and marriage may similarly lead to some reassessment of food habits (Tremolières, 1970).

Leaving aside the nutritionist's problems of contact, there is simply the question of what data about problems of food consumption and food choice are available. Since the National Food Survey Committee began annual monitoring of food consumption, nutritionists have relied extensively on its findings, despite the limitations of its report as a measure of changing dietary patterns because it presents nothing which explains changes in food preferences or choice. Furthermore, little evidence is available currently of the regional variation in food consumption and meal patterns so vividly portrayed in David Allen's book British Tastes (Allen, 1968), or of the extent of nutritional knowledge in the population. Since Brown, McKenzie \& Yudkin ( 1963 ), studied the nutritional knowledge of housewives in Bromley, later surveys which have been carried out tend to confirm the view of its limited and often inaccurate nature, and in particular the separation of general knowledge about what is 'good' for you from an understanding of nutrition (UK Margarine and Shortening Manufacturers' Association, 1969). In other examples, such as the National Child Development Study (Davie, Butler \& Goldstein, I 972 ) no nutritional studies were included in the programme other than a survey of the extent and duration of breast-feeding practices. Thus the nutritionist is still largely in the dark about factors affecting food choice (ARC/MRC Committee, 1974), and in some instances is positively confused. Den Hartog (1966), for example, suggested that in The Netherlands 'the ignorance of the population causes an incorrect choice of foods', but at the same time was prepared to assert that 'It is readily demonstrable that the nutritional knowledge of the population has considerably increased. However, the factors preventing the application of this knowledge in practice are unknown'. The nutritionist has therefore an urgent task to collect facts about food choice and dietary habits; unfortunately, to take up a point raised in the Neuberger report (ARC/MRC Committee, 1974), this seems to be the most unpopular and unattractive aspect of nutrition research at present. Even this by itself would be insufficient: after all, numbers of nutrition education programmes have already been carried out (Whitehead, I973). Significantly, no adequate refutation has yet appeared of 
McKenzie \& Mumford's ( 1965$)$ review of the literature, in which they found little effective evaluation of nutrition education programmes.

The problem of obesity illustrates these points. An advertisement by a firm largely connected with food manufacturing tells me that half the nation is overweight; but there is little or no evidence available regarding the incidence of obesity in Britain. There has been no national survey of the problem. In a sample of 2000 adults, McKenzie (1967) found that $25 \%$ had attempted to reduce weight; among women the value was as high as $35 \%$. Undoubtedly, large numbers of overweight people have a self-image which prompts them to slim and in the process most of them will attempt some change in the patterns of food consumption (Yudkin, 1968). In this they face a bewildering choice of advice but little opportunity for long-term supervision. Some organized slimming has achieved a remarkably high motivation among its adherents, but no longterm evaluation of the effect of this form of nutrition education has been achieved. In fact, it is doubtful if these measures have any permanent effect (McKenzie, 1967; Office of Health Economics, 1969; A. E. Bender, personal communication).

Of course, as I have already suggested, the type of information available depends greatly on the outlet. So much is based on advertising that its influence on food choice must not be ignored (Baker \& MacIntyre, I965). Similarly, cookery writers reach a very wide audience (Patten, 1969). In both instances the accuracy and suitability of the nutritional information is often limited due to an over-selective use of facts or to the low priority of nutrition as a promotional device. My contention is that accurate, easily-understood nutritional information is not available as an alternative: nutritionists, despite a considerable amount of popular writing, have no commonly-agreed, coherent message to be applied in nutrition education programmes. Indeed, in a society of relative affluence, their message has become essentially a negative one; to reduce consumption, either generally or selectively, is both unpopular and counter to the philosophy of the consumer society. After all, for people conditioned to consume, self-denial is unacceptable and stressful, and the great success of slimming foods and dietary supplements is that they allow consumption to continue and, through a process of self-deception, prevent reduction of intakes or change in dietary patterns taking place.

\section{Conclusion}

The problems of nutrition education which I have attempted to outline are complex and require a long-term approach. The message of the 1967 Nutrition Society symposium on 'Nutrition and the public health' that 'we still have to devise means by which a detailed comprehensive picture of the nation can be achieved' (Berry, 1968) is as true 8 years later as when it was written.

To summarize, we can all agree first that nutrition is now a well-established, comprehensive body of theoretical knowledge. Secondly, and I think far less obviously, this theoretical knowledge cannot automatically be used as educational material without a careful process of adaptation, to which, until now, nutritionists have paid little attention. Thirdly, nutritionists who wish to utilize their 
professional knowledge to change patterns of behaviour must be prepared to collect adequate data about their target community; to formulate objective standards by which to assess nutritional status and to establish programme objectives; to study and apply educational techniques in their programmes; and to learn evaluation techniques and apply them as rigorously as in laboratory experiments.

Such a strategy for nutrition education must involve nutritionists in closer contact with social scientists to obtain an understanding of the social structure of the target community and of the dynamics of social change, since the institutional framework of a society, its social attitudes and its ethos will affect its receptivity to nutrition education programmes.

Finally, there remains the problem of funding nutrition education, most of which has consisted hitherto of small-scale and fragmentary studies. It may not seem easy to obtain sufficient funds in the present economic recession, but the essence of future progress in nutrition education must be in co-ordinated studies: the day of the small-scale survey should be over now that we have computer techniques of dietary analysis. Unless nutritionists can exert sufficient pressures to fund a centre for nutrition policy and education, the likelihood of success is limited. What is required among nutritionists, therefore, is a positive political attitude to press for adequate research funds from research councils and foundations in order to develop large-scale programmes independent of commercial pressures. The task ahead for committed nutrition educators must be to re-establish nutritional science as a determinant of social policy.

\section{REFERENCES}

Allen, D. E. (1968). British Tastes. London: Hutchinson.

ARC/MRC Committee (1974). Food and Nutrition Research Report of the ARC/MRC Committee. London: H.M. Stationery Office.

Baker, A. Z. \& MacIntyre, A. W. D. (1965). Hlth Educ. F. 23-24, 144.

Berry, W. T. C. (1968). Proc. Nutr. Soc. $27, \mathrm{I}$.

Brown, A. M., McKenzie, J. C. \& Yudkin, J. (1963). Proc. Nutr. Soc. 22, ix.

Carr-Saunders, A. M. (1937). Political Q. 8, 227.

Davie, R., Butler, N. R. \& Goldstein, H. (1972). From Birth to Seven. London: Longmans.

Den Hartog, C. (1966). Wld Rev. Nutr. Diet. 6, 90.

M'Gonigle, G. C. M. (1933). Proc. R. Soc. Med. 26, 677.

McKenzie, J. C. (1967). \%. Market Res. Soc. $9,77$.

McKenzie, J. C. \& Mumford, P. M. (1965). Wld Rev. Nutr. Diet. 5, 21.

Marrack, J. R. (1937). The Highroay 39, 112.

Ministry of Health (1937). Advisory Committee on Nutrition: First Report. London: H.M. Stationery Office.

Newson, J. \& Newson, E. (1963). Patterns of Infant Care in an Urban Community. London: Allen \& Unwin.

Office of Health Economics (1969). Obesity and Disease. London: Office of Health Economics.

Patten, M. (1969). Getting the Most out of Food, vol. 5, p. 35. London: Van den Burghs \& Jurgens Ltd.

Pyke, M. (1967). The Listener 77, 35I.

Tape, N. W. \& Sabry, Z. I. (I 669 ). Wld Rev. Nutr. Diet. I0, I.

Tremolières, J. (1970). Proc. Nutr. Soc. 29, 285.

UK Margarine and Shortening Manufacturers' Association (r969). Food, Facts and Fallacies. London: UK Margarine and Shortening Manufacturers' Association.

Week-End Review (1933). Weekend Rev. 1 April, p. 357.

Whitehead, F. E. (1973). Wld Rev. Nutr. Diet. 1 7, 91 .

Yadkin, J. (1968). Practitioner 201, 330 .

\section{Printed in Great Britain}

